\title{
Academician S. N. Vernov and cosmic ray variations research in the former USSR
}

\author{
L. Dorman ${ }^{1,2}$ \\ ${ }^{1}$ Israel Cosmic Ray and Space Weather Center, Tel Aviv University and Israel Space Agency, Israel \\ ${ }^{2}$ Cosmic Ray Department, N. V. Pushkov IZMIRAN, Russian Ac. of Sci., Russia
}

Correspondence to: L. Dorman (lid@ physics.technion.ac.il)

Received: 15 November 2010 - Revised: 23 October 2011 - Accepted: 16 November 2011 - Published: 18 June 2012

\begin{abstract}
During my long scientific career of about 60 years (from 1951), I was happy to meet and cooperate with Academician S. N. Vernov. During the first step (1950-1952), S. N. Vernov together with N. V. Pushkov organized the first Soviet network of cosmic ray (CR) stations equipped by large automatically operating ionization chambers of A. Compton type shielded by $10 \mathrm{~cm}$ of $\mathrm{Pb}$. This was the beginning of the $\mathrm{CR}$ variations research in the former USSR. In the present paper I consider step by step the development of experimental and theoretical basis of $\mathrm{CR}$ variations research in the former USSR and the great role of S. N. Vernov in this process.
\end{abstract}

1 D. V. Skobeltsyn and S. N. Vernov as organizers of education in nuclear and cosmic ray physics in the USSR

In order to educate skilled personnel for the Soviet atomic science and engineering, including cosmic ray (CR) and space research, immediately after the 2nd World War, the Institute of Nuclear Physics together with the Department of Nuclear Physics within the framework of the Physical Faculty of M. V. Lomonosov Moscow State University were organized. Both were headed by academician D. V. Skobeltsyn. Prof. S. N. Vernov became his deputy, and in 1960 succeeded him in heading these units that educated for the former USSR and many other countries a great number of first class specialists. S. N. Vernov, who played a vital role in formation of CR variations research (as well as many other branches of CR and space science in the former USSR), was born on 11 July 1910 in the small town of Sestroretsk near St. Petersburg. Upon his graduation in 1931 from the Leningrad Polytechnic Institute, he entered the Radium Institute as a postgraduate student, where he developed the technique of studying CRs in stratosphere by using small bal-

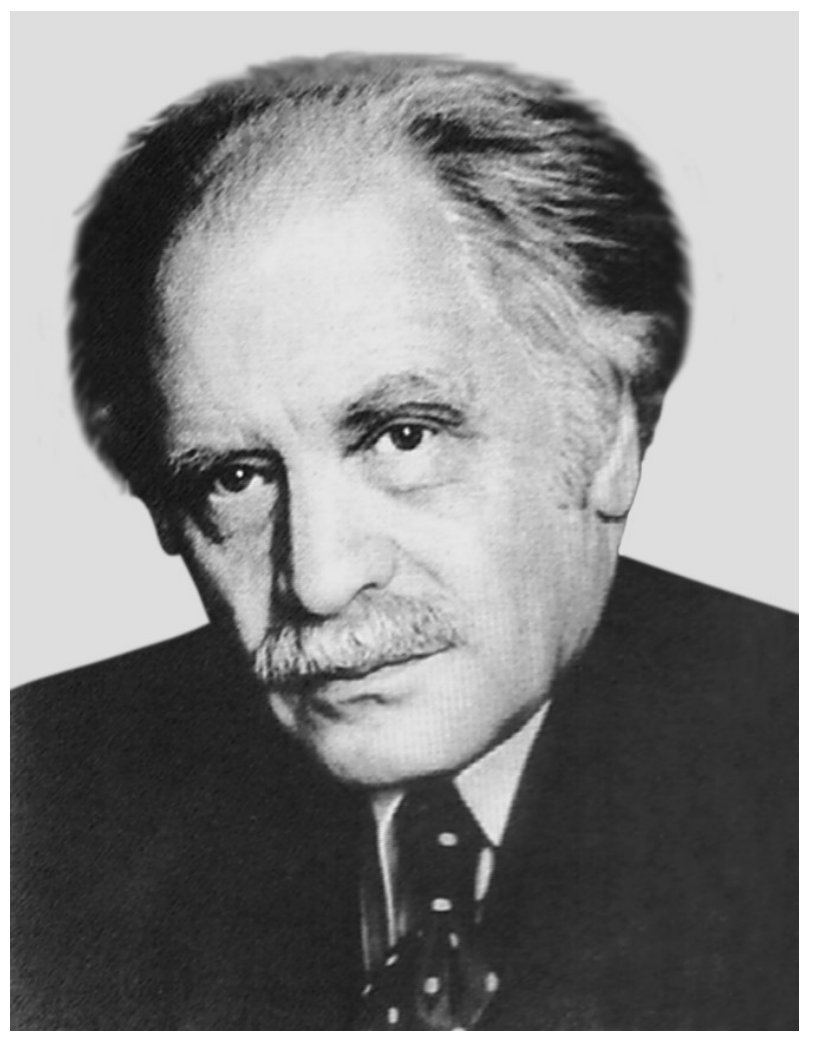

Fig. 1. Academician Sergei Nikolaevich Vernov (1910-1982)

loon high-altitude automatic radio-sondes. In 1935 he was awarded a $\mathrm{PhD}$ degree and entered for doctoral candidacy the P. N. Lebedev Physical Institute in Moscow. Under supervision of academicians D. V. Skobeltsyn and S. I. Vavilov, he began to study the nature of primary CRs by using the method of radio-sondes and in 1939, he defended his doctoral dissertation. In 1953, S. N. Vernov (see Fig. 1) was 


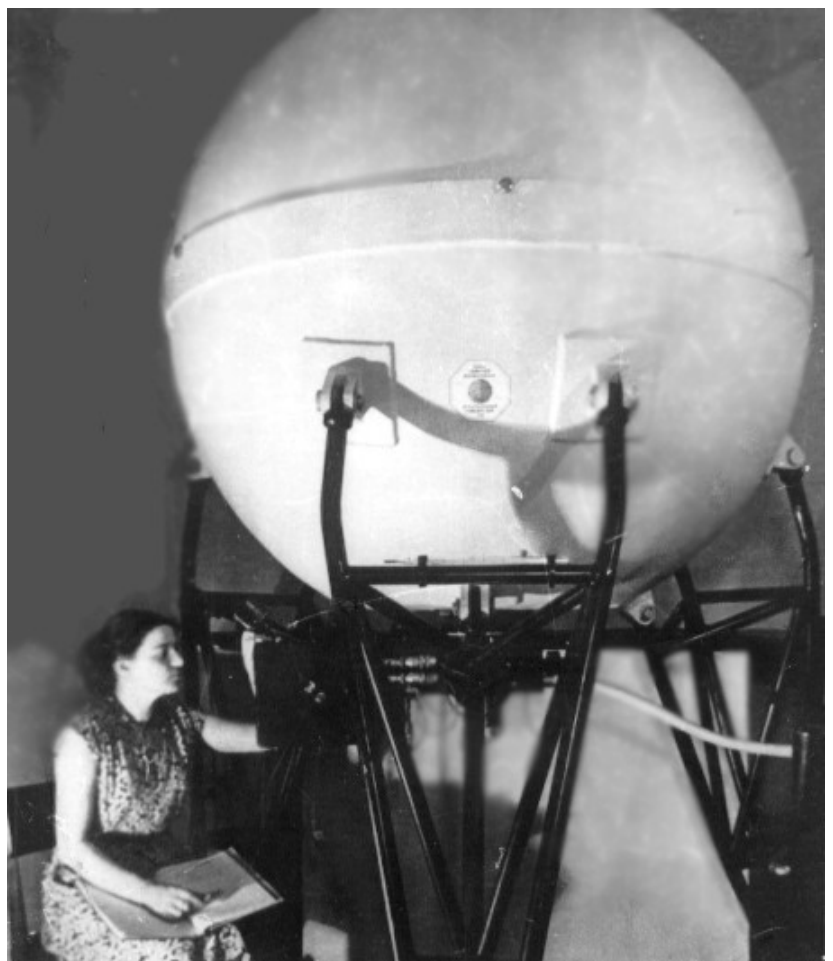

Fig. 2. A view of ASC-1. The young lady near the chamber is one of the designers of this type of chamber, State Prize winner Galina Shafer (Tyanutova), an enthusiast and propagandist of this detector.

elected a corresponding member, and in 1968 a full member of the USSR Academy of Sciences.

\section{The first Soviet network of CR stations equipped with ionization chambers}

After graduation in December 1950 from Moscow Lomonosov State University (Nuclear Physics Division, the Team of Theoretical Physics), my supervisor Prof. D. I. Blokhintsev planned for me, as a winner of a Red Diploma, to continue my education as an aspirant (a graduate student) and prepare for my $\mathrm{PhD}$ in his very secret objective within the framework of what was in those times called the Atomic Problem. To my regret, the KGB withheld permission, and I, together with other Jewish students who had graduated from the Nuclear Divisions of Moscow and Leningrad Universities and Institutes, were faced with a real prospect of being without any work. It was our good fortune that at that time there was being brought into being the new Cosmic Ray Project (what at that time was also very secret, but not so much as the Atomic Problem), and after some time we were directed to work within the framework of this Project. It was organized and headed by Prof. S. N. Vernov and Dr. N. V. Pushkov, Director of NIIZM (now IZMIRAN); Prof. E. L. Feinberg led the theoretical part, and
Dr. Yu. G. Shafer the experimental part of the Project. Within the framework of this Project there was organized, in former Soviet Union in 1951, a wide network of CR stations equipped with a A. Compton type of large ASC-1 (9501) and ASC-2 (501) ionization chambers developed and produced in the former USSR (see Fig. 2). In several months we had received additional education in NIIZM in solar and solar-terrestrial physics, and in geophysics. After that, we were sent to work on the different newly-founded CR stations (NIIZM near Moscow, Sverdlovsk, Irkutsk, Yakutsk, Cape Schmidt, Bay Tikhaja, and Tbilisi). So, at the end of 1951, the first Soviet CR network of stations, equipped with ionization chambers, began to work. One ASC-1 was also prepared for the newly-founded Chinese CR station in Beijing (see Fig. 3, picturing participants of the meeting where the agreement with China was signed).

\section{Preparing for the IGY (International Geophysical Year): neutron monitors and counter telescopes, par- ticipation in ICRC, and the first monograph on CR variations}

Within the framework of preparing the Soviet network of CR stations to take part in the International Geophysical Year (IGY, during July 1957-December 1958), S. N. Vernov, in 1955 , founded and headed a special section of cosmic ray variations at the Academy of Science of the former USSR and asked me to be his deputy (after several years this section was named "Cosmic Ray Variations and Radiation Belts", and after 1982 I headed it). This section organized the production of the J. A. Simpson's type neutron monitors and cubic counter telescopes for the Soviet network of CR stations. At that time, many experimental results on $\mathrm{CR}$ time variations were obtained, but they were considerably affected by meteorological effects and by meson-nuclear cascade in the atmosphere. Therefore, it was not possible to make reasonable transformation from observed CR time variations in the atmosphere and underground to the variations expected in space. To solve this problem, I developed, in 1952-1954, a full theory of cosmic ray meteorological effects and a special method of coupling functions between primary and secondary CR variations. In 1955, the former USSR took part for the first time in the International Cosmic Ray Conference (ICRC) that was held in Mexico. At this conference, S. N. Vernov presented papers from the former USSR, including our paper about $\mathrm{CR}$ variations (theory of CR meteorological effects, method of coupling functions, and the nature of different types of CR variations). Moreover, in 1955, I was working on my PhD thesis in Lebedev Physical Institute in Moscow, where it was recommended that I would publish my dissertation as a monograph, and then present it as a dissertation for the doctor of science degree. S. N. Vernov, as usual, helped very much to organize this publication. In the beginning of 1956, the manuscript of the book was mostly 


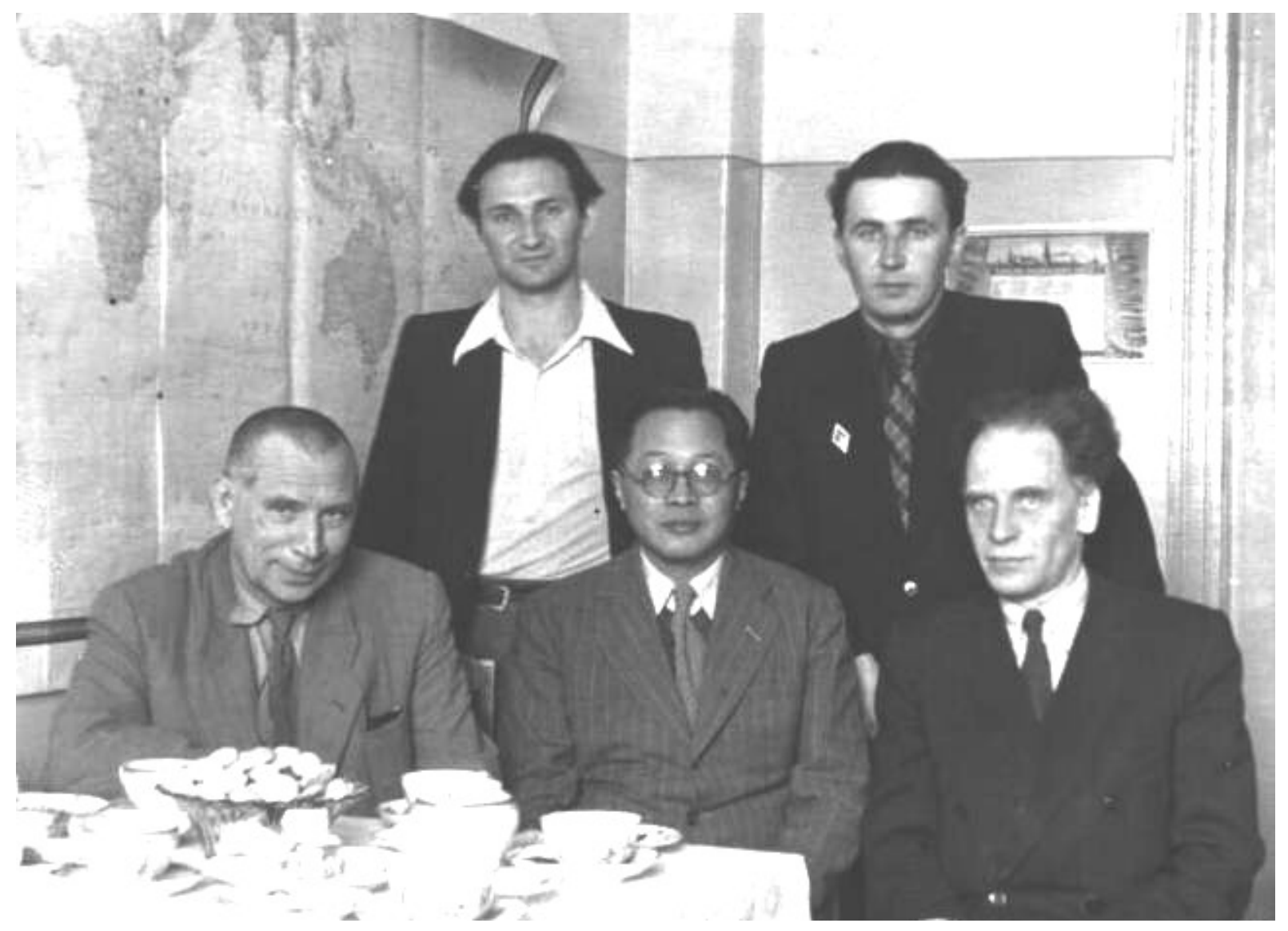

Fig. 3. The meeting in IZMIRAN where the agreement on the foundation of the CR station in China, equipped by big ionization chamber, was signed. From left to right: N. V. Pushkov, L. I. Dorman, representative from China, Yu. M. Kopylov, and S. N. Vernov.

ready, but on 23 February 1956 occured the biggest observed Ground Level Enhancement (GLE) for which unique data by the first Soviet network of CR stations was obtained (with maximum amplitude of intensity increase about $200 \%$ in the ionization chamber of IZMIRAN and about $5000 \%$ in the neutron monitor of Chicago). I added to my dissertation a special chapter concerning this event and the first book about CR variations was published in Russian in Moscow at the beginning of the IGY in July 1957. After a few months it was published in English in the USA.

\section{Preparing for the IQSY (International Quiet Sun Year) and very fortuitous, big mistake of the Govern- ment's bureaucrats}

In 1959-1960, S. N. Vernov together with N. V. Pushkov prepared a special project for the Soviet Government and Central Committee of Communist Party of the former USSR to take an active part in International Quiet Sun Year (IQSY, 1964-1965). The Project was prepared in old currency, before the financial reform of 1 January 1961. The CR part of Project was prepared by Ya. L. Blokh and L. I. Dorman.
This project was finally considered and signed by the PrimeMinister in the beginning of 1961, several days after the monetary reform of 1 to 10 , and because of a very fortuitous, big mistake of the Government's bureaucrats, the total financing of the Project unexpectedly increased tenfold (money to build new buildings, for new equipment, for salaries, and so on). Let me note that S. N. Vernov and N. V. Pushkov, as members of Communist Party, decided immediately to inform the Soviet Government and Central Committee of Communist Party about this mistake. Only thanks to the great pressure from our side and the very firm promise not to reveal to anybody this secret for at least 45 years, S. N. Vernov and N. V. Pushkov agreed with us to realize the project according to the new budget. It meant that instead of small stations, it became possible to organize many new institutes with much better equipment. For example, for CR we organized the production of new large neutron counters NM-15 (with diameter $15 \mathrm{~cm}$ and length $200 \mathrm{~cm}$ ). We developed and produced many neutron supermonitors (see Fig. 4) with an effective area of $18 \mathrm{~m}^{2}$ instead of small neutron monitors of IGY type with an effective area of about $2 \mathrm{~m}^{2}$, mainly thanks to the great help of S. N. Vernov and effective activity of 


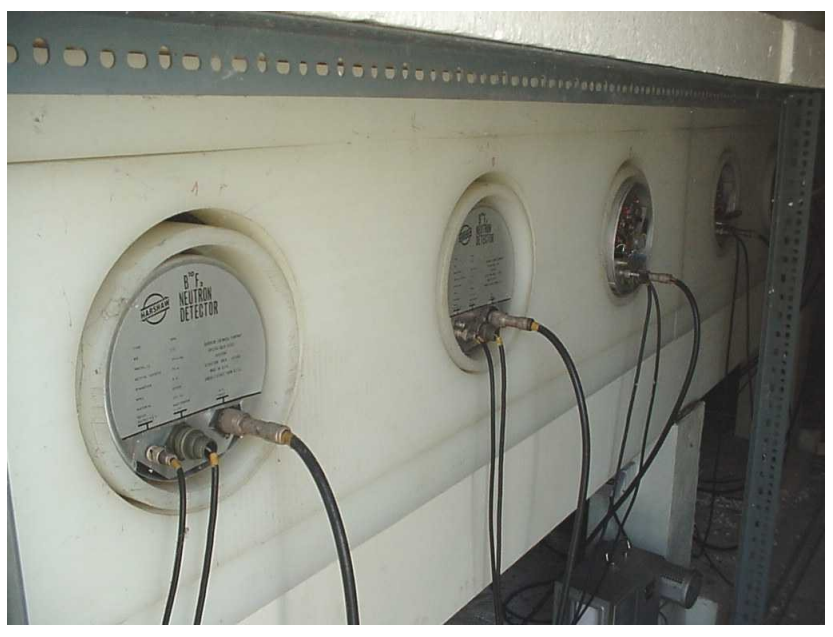

Fig. 4. Neutron supermonitor in IZMIRAN

Ya. L. Blokh (see Fig. 5). To educate students in the new field of science, I began to give lectures at the Universities in Moscow (continued during about 30 years) Irkutsk, AlmaAta, and Nalchik. Thanks to the scientific and organizational activity of S. N. Vernov, the realization of this Project gave great support for sufficiently increasing the experimental and theoretical basis of CR variations research as well as in other fields of Solar-Terrestrial physics in the former USSR.

\section{Conclusions}

In conclusion, let me underline: the science on $\mathrm{CR}$ variations in the former Soviet Union was mainly founded and developed thanks to special properties of S. N. Vernov as a great scientist, teacher, and organizer of science.

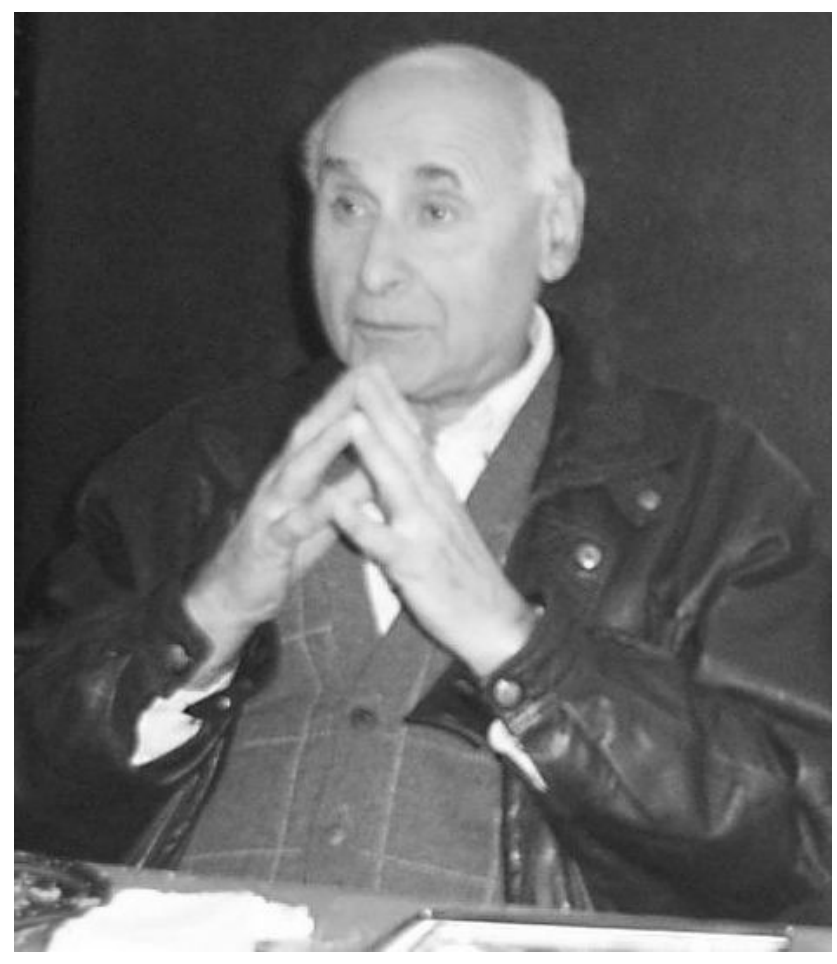

Fig. 5. Yakov Leonovich Blokh

Acknowledgements. My great gratitude to Ya. L. Blokh, O. I. Inozemtseva, N. S. Kaminer, and L. Kh. Shatashvili with whom we started to work on CR variations at 1951, and to my former students A. V. Belov, E. A. Eroshenko, R. T. Gushchina, and V. G. Yanke, who effectively continued the research of CR variations in IZMIRAN until present time. My great gratitude to both referees and editor for the useful comments, and F. Keshtova for the help to improve English.

Edited by: R. Vainio

Reviewed by: H. Fichtner and H. Mavromichalaki 